\title{
Frontal placement of dispersive patch for effective ablation of arrhythmia originating from the anterior right ventricular outflow tract
}

\author{
Piotr Futyma $^{1}$ (D) Piotr Kulakowski ${ }^{1,2}$
}

Received: 11 March 2017 / Accepted: 1 June 2017 / Published online: 17 June 2017

(C) Springer Science+Business Media, LLC 2017

Keywords Catheter ablation · Anterior right ventricular outflow tract $\cdot$ Dispersive patch

A 50-year-old female after unsuccessful radiofrequency catheter ablation (RFCA) of premature ventricular complexes (PVCs; $>45,000$ on 24-h Holter ECG) arising from the anterior right ventricular outflow tract (RVOT) was referred for redo procedure. Standard RFCA (power up to $70 \mathrm{~W}$ and temperature up to $70{ }^{\circ} \mathrm{C}$ ) failed again to abolish arrhythmia. Therefore, we decided to relocate the dispersive patch electrode (DPE) from the standard back location to a frontal chest position in order to redirect RF current towards the anterior aspect of the RVOT (Fig. 1c). The position of the ablation catheter remained constant, which was confirmed by repeated fluoroscopic LAO $45^{\circ}$ and RAO $45^{\circ}$ views and unchanged intracardiac signals. A single RF application $\left(31 \mathrm{~W}, 55{ }^{\circ} \mathrm{C}\right)$ immediately terminated PVCs. During a 4-month follow-up, the patient remained asymptomatic and 24-h Holter ECG showed only 40 PVCs. A possibility of creating deeper RF lesions by adjustment of DPE location has been suggested in a few studies [1,2]; however, this approach has never been implemented into everyday practice. This case report shows that DPE frontal placement enables effective RFCA of arrhythmias originating from the anterior RVOT.

Piotr Futyma

piotr.futyma@gmail.com

1 Invasive Cardiology Department, St. Joseph's Heart Center, Anny Jagiellonki 17, 35-623 Rzeszów, Poland

2 Department of Cardiology, Postgraduate Medical School, Grochowski Hospital, Warsaw, Poland

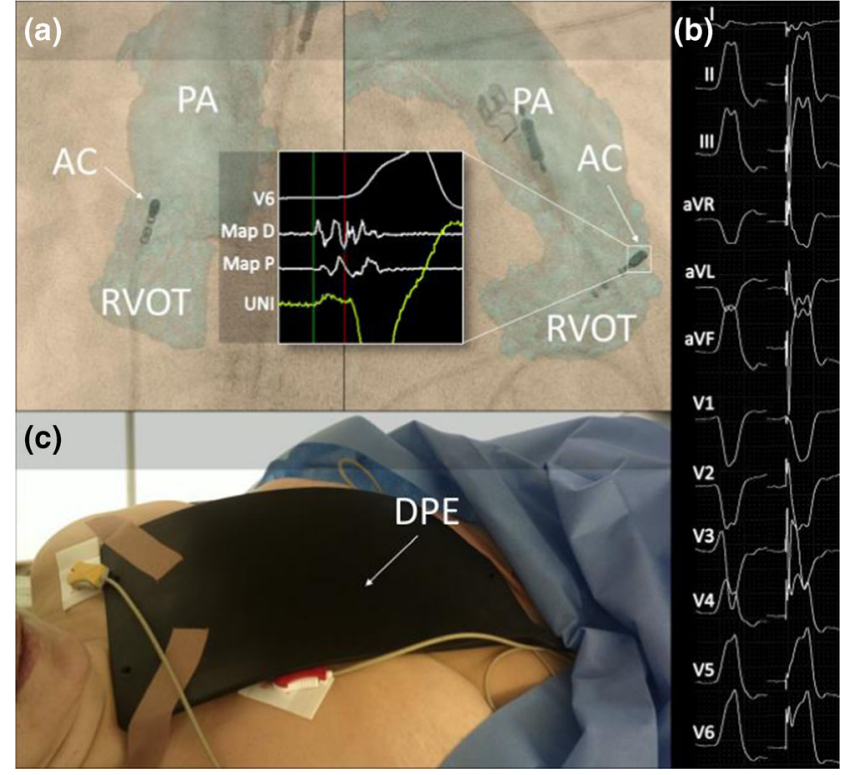

Fig. 1 a Fluoroscopic images of the right ventricular outflow tract (RVOT) and pulmonary artery $(P A)$ reconstructed and fused using EP Navigator tool (Philips Healthcare, Best, Netherlands) (LAO $45^{\circ}$ and RAO $45^{\circ}$ ) with local signal (Map D) recorded from the ablation catheter $(A C)$ preceding PVC's onset by 37 msec. b Clinical PVC with acceptable pacemapping. c Dispersive patch electrode $(D P E)$ placed in a frontal position

Compliance with ethical standards

Conflict of interest The authors declare that they have no conflict of interest.

\section{References}

1. Nath S, DiMarco JP, Gallop RG, McRury ID, Haines DE. Effects of dispersive electrode position and surface area on electrical parameters and temperature during radiofrequency catheter ablation. Am J Cardiol. 1996;77:765-7.

2. Jain MK, Tomassoni G, Riley RE, Wolf PD. Effect of skin electrode location on radiofrequency ablation lesions: an in vivo and a threedimensional finite element study. J Cardiovasc Electrophysiol. 1998;9: $1325-35$. 